\title{
Variable apoptotic response of NSCLC cells to inhibition of the MEK/ERK pathway by small molecules or dominant negative mutants
}

\author{
J Brognard ${ }^{1}$ and PA Dennis ${ }^{\star, 2}$ \\ ${ }^{1}$ Cancer Therapeutics Branch, Center for Cancer Research, National Cancer \\ Institute, Bethesda, MD 20889, USA \\ $2 \mathrm{NCI} /$ Navy Medical Oncology, National Naval Medical Center, Bethesda, MD \\ 20889, USA \\ * Corresponding author: PA Dennis, NCl/Naval Medical Oncology, Building 8, \\ Room 5101, 8901 Wisconsin Ave., Bethesda, MD 20889, USA. \\ Tel: 301-496-0901; Fax: 301-496-0047; E-mail: pdennis@nih.gov
}

Received 5.9.01; revised 13.2.02; accepted 22.2.02

Edited by C J Thiele

\begin{abstract}
To evaluate the role of the MEK/ERK pathway in NSCLC survival, we analyzed NSCLC cell lines that differed in tumor histology and status of p53, Rb, and K-ras. Constitutive ERK1/2 activity was demonstrated in 17 of 19 cell lines by maintenance of ERK1/2 phosphorylation with serum deprivation. Phosphorylation of ERK1/2 correlated with phosphorylation of MEK1/2 and p90RSK, but was inversely correlated with phosphorylation of c-Raf at S259. With serum deprivation, the MEK inhibitors, PD98059 and U0126, inhibited ERK1/2 activity but did not increase apoptosis. PD98059 and U0126 induced cell cycle arrest in $G_{0} / G_{i}$ in cells with the highest levels of ERK $1 / 2$ activity, which correlated with induction of p27 but not p21. To confirm the cytostatic response to MEK inhibitors, we performed transient transfections with dominant negative forms of MEK or ERK. Surprisingly, dominant negative MEK and ERK mutants increased apoptosis without affecting cell cycle or p27 levels. When combined with paclitaxel, MEK inhibitors had no effect on apoptosis. In contrast, dominant negative ERK2 potentiated paclitaxel-induced apoptosis. Our studies show that constitutive ERK1/2 activity in NSCLC cells promotes cellular survival and chemotherapeutic resistance. Moreover, our data are the first to demonstrate divergent cellular responses to inhibition of the MEK/ERK pathway by small molecule inhibitors or dominant negative mutants.

Cell Death and Differentiation (2002) 9, 893-904. doi:10.1038/ sj.cdd. 4401054
\end{abstract}

Keywords: ERK; kinase; apoptosis; chemotherapy; lung cancer

Abbreviations: MAPK, mitogen activated protein kinase; ERK, extracellular signal-regulated kinase; MEK, mitogen-activated protein kinase/ERK kinase; DNM, dominant negative mutant; PI3$\mathrm{K}$, phosphatidylinositol 3- kinase; NSCLC, non small cell lung cancer; GST, glutathione S-transferase; GFP, green fluorescent protein; IGF-I, insulin-like growth factor-I; LSB, Laemmli sample buffer

\section{Introduction}

The mitogen activated protein kinase (MAPK) family is composed of three subfamilies that serve to coordinate key cellular processes such as gene regulation, cellular differentiation, cellular growth, and cell death with extracellular stimulation by growth factors, cytokines, and phorbol esters (reviewed in ${ }^{1}$ ). The extracellular signal-regulated kinase (ERK) subfamily of MAP kinases promotes cellular survival by successive phosphorylation of mitogen-activated protein kinase/ERK kinase (MEK), ERK, and downstream substrates such as Elk-1 and p90RSK. Activation of the MEK/ERK pathway may contribute to tumorigenesis or cancer growth, because activated MEK or ERK has been observed in many tumor cell lines and primary tumors. ${ }^{2}$ These observations led to the hypothesis that targeting the MEK/ERK pathway might have therapeutic value in cancer, and thus prompted the development of approaches to inhibit this pathway. This hypothesis was validated recently, as Sebolt-Leopold et al. showed that a small molecule MEK inhibitor attenuated the growth of colon cancer cells in mice. ${ }^{3}$

Lung cancer is the most lethal form of cancer for both men and women in the US, with over 150000 deaths in 1998. ${ }^{4}$ Non-small cell lung cancer (NSCLC) comprises the majority of lung cancer (over $75 \%$ ), and when clinically extensive, is typically characterized by inexorable disease progression despite treatment with chemotherapy and/or irradiation. To better understand the biochemical basis for therapeutic resistance of NSCLC cells, we began an analysis of activation of signal transduction pathways in NSCLC cell lines. Using small molecule inhibitors and dominant negative mutants (DNMs), we recently demonstrated that the PI3K/Akt pathway is constitutively active in a majority of NSCLC cell lines and promotes both cell survival and therapeutic resistance. ${ }^{5}$ In that study, two cell lines, A549 and H1355, had low levels of Akt activity yet were resistant to chemotherapy. Because both the PI3K/Akt pathway and MEK/ERK pathway are activated by $K$-ras mutations (which are common in NSCLC), we tested whether the MEK/ERK pathway was active in NSCLC cell lines, and whether the therapeutic resistance of cells with low Akt levels was related to activation of other signaling pathways such as the MEK/ERK pathway. Our data show that in addition to the PI3K/Akt pathway, the MEK/ERK pathway is constitutively active in the majority of NSCLC cell lines and promotes cellular survival and resistance to chemotherapy in NSCLC cells. In these studies, however, 
the use of small molecule inhibitors and DNMs resulted in divergent cellular responses. The importance of the ERK pathway was only effectively demonstrated by using DNMs.

\section{Results}

\section{ERK1/2 is constitutively active in NSCLC cells}

To determine whether ERK1/2 is active in NSCLC cells, we analyzed cell lines established at the $\mathrm{NCl} / \mathrm{National} \mathrm{Naval}$ Medical Center that varied in histology and status of $\mathrm{p53}, \mathrm{Rb}$, and $K$-ras. ${ }^{6}$ Cells were grown under normal growth conditions (10\% FBS) or serum-deprived overnight (0.1\% FBS), and ERK activity was assessed indirectly by measuring the phosphorylation status of amino acids necessary for ERK activity (T202/Y204 for ERK1 and T183/Y185 for ERK2) using phospho-specific antibodies in immunoblotting experiments. Under normal growth conditions, 18/19 NSCLC cell lines (95\%) exhibited phosphorylation of ERK1/2 (data not shown). When serum starved, phosphorylation was observed in 17/19 $(89 \%)$ cell lines (Table 1). Levels of native ERK did not change with serum deprivation (data not shown). The fact that ERK1/2 phosphorylation was observed in $89 \%$ of NSCLC cell lines when cultured in low serum, a condition where ERK phosphorylation is commonly decreased or absent, suggested that ERK1/2 was constitutively active in NSCLC cells and that it might contribute to NSCLC survival.

To investigate this pathway more fully, we chose three NSCLC cell lines with constitutive ERK1/2 phosphorylation that varied in endogenous Akt activity: H1155 (high Akt activity); A549 and H1355 (low Akt activity). Figure 1 shows that $\mathrm{H} 1155$ cells had the highest levels of $\mathrm{c}$-Raf phosphorylated at S259, an Akt site. H1155 cells had the

Table 1 Survey of NSCLC cell lines for phosphorylation of ERK $1 / 2$

\begin{tabular}{lccccc}
\hline $\begin{array}{l}\text { NSCLC } \\
\text { LINES }\end{array}$ & $\begin{array}{c}\text { P-ERK1/2 } \\
\text { in LS }\end{array}$ & $\begin{array}{c}\text { Rb } \\
\text { Status }\end{array}$ & $\begin{array}{c}\text { Tumor } \\
\text { Histology }\end{array}$ & $\begin{array}{c}\text { p53 } \\
\text { Status }\end{array}$ & $\begin{array}{c}\text { Kras } \\
\text { Status }\end{array}$ \\
\hline H1703 & + & WT & SQ & Mut & WT \\
H157 & + & $*$ & SQ & WT & Mut \\
A549 & + & WT & SQ & WT & WT \\
H1155 & + & Mut & LC & Mut & Mut \\
H1355 & + & WT & AD & Mut & Mut \\
H1334 & + & WT & LC & Mut & WT \\
H460 & + & WT & LC & WT & Mut \\
H1299 & + & WT & LC & Mut & Mut \\
H727 & + & WT & CA & Mut & Mut \\
H838 & + & WT & AD & WT & WT \\
H2228 & - & Mut & AD & WT & WT \\
H2594 & + & WT & ME & $*$ & $*$ \\
H2444 & - & WT & $*$ & $*$ & $*$ \\
H2009 & + & $*$ & AD & Mut & Mut \\
H2409 & + & WT & AD & $*$ & $*$ \\
H3072 & + & WT & $*$ & $*$ & $*$ \\
H2850 & + & WT & $*$ & $*$ & $*$ \\
H2973 & + & WT & $*$ & $*$ & $*$ \\
H1374 & + & WT & $*$ & $*$ & $*$ \\
\hline
\end{tabular}

Lysates were prepared from cells exposed to $0.1 \%$ FBS overnight. Immunoblotting was performed with phospho-specific ERK1/2 and native ERK $1 / 2$ antibodies. (+) indicates presence of phosphorylated ERK1/2. (-) indicates that there was no detectable ERK1/2 phosphorylation. $\left(^{*}\right)$ indicates that the histology or status is unknown. Histologic definitions: $S Q$, squamous cell carcinoma; LC, large cell carcinoma; CA, carcinoid; AD, adenocarcinoma; ME, mesothelioma lowest levels of phosphorylated MEK1/2, ERK1/2, and p90RSK (a downstream substrate of ERK1/2 that can promote cellular survival ${ }^{7}$ ), which is consistent with inhibition of the ERK pathway due to c-Raf phosphorylation by Akt at $\mathrm{S} 259 .^{8}$ In contrast, A549 and $\mathrm{H} 1355$ cells had low levels of c-Raf phosphorylation at S259, and high levels of MEK1/2, ERK1/2, and p90RSK phosphorylation. The ratio of phosphorylated to total ERK was highest in the H1355 cells. There was no variation in protein levels of MKP-1, a phosphatase that regulates ERK activity. In addition, there was no variation in phosphorylation patterns with serum deprivation with or without administration of IGF-I (except for an increase in MEK1/2 and ERK1/2 phosphorylation in the $\mathrm{H} 1155$ cells). The fact that IGF-I stimulated MEK1/2 and ERK1/2 phosphorylation in $\mathrm{H} 1155$ cells without further increasing S259 phosphorylation demonstrates that phosphorylated c-Raf can still be activated by upstream stimuli. This is consistent with earlier studies that showed an approximate twofold induction of c-Raf activity when S259 was mutated to A259. ${ }^{9}$ These studies suggested an inverse relationship between Akt activity and ERK activity in these three NSCLC cell lines, and showed that A549 and H1355 cells had the highest levels of activation of the MEK/ERK pathway.

\section{MEK inhibitors decrease constitutive ERK activity and cause NSCLC cell cycle arrest in $G_{0} / G_{1}$}

To determine the cellular response of NSCLC cells to inhibition of constitutive ERK1/2 activity, we treated NSCLC cells with two commercially available MEK inhibitors, PD98059 ${ }^{10}$ and U0126, ${ }^{11}$ under conditions of serum deprivation. Figure 2A (upper two gels) shows that after $2 \mathrm{~h}$ of incubation both compounds inhibited ERK1/2 phosphorylation. The near complete inhibition of ERK1/2 phosphorylation by these compounds may reflect the fact that the NSCLC cells were serum deprived overnight prior to administration of the MEK inhibitors. Phosphorylation of ERK1/2 was inhibited less with U0126 $(10 \mu \mathrm{M})$ than PD98059 $(25 \mu \mathrm{M})$, but differences in potency may be related to differences in structure, uptake, or cell type specific metabolism of these compounds. ${ }^{12}$ ERK $1 / 2$ activity, as assessed by phosphorylation of a downstream substrate, Elk-1, was detected in all three cell lines and was inhibited by U0126 or PD98059 (Figure 2A, lower gel (PD98059 kinase assay not shown)). H1155 cells, which had the lowest levels of phosphorylated ERK $1 / 2$, had the lowest levels of ERK1/2 activity. ERK1/2 phosphorylation correlated with ERK1/2 activity in these three NSCLC cell lines, as well as $\mathrm{H} 157, \mathrm{H} 1703, \mathrm{H} 1299$, and $\mathrm{H} 727$ cells from Table 1 (data not shown), consistent with numerous reports showing that ERK phosphorylation correlates with ERK activity. Inhibition of ERK1/2 phosphorylation and kinase activity by a single treatment of PD98059 and U0126 with serum deprivation was maintained up to $96 \mathrm{~h}$ (data not shown).

In spite of inhibition of constitutive ERK1/2 activity with PD98059 or U0126, there was no significant effect on apoptosis when cells were serum-starved for $48 \mathrm{~h}$ (Figure $2 \mathrm{~B}$ ). Cell cycle analysis (Figure $2 \mathrm{C}$ ) revealed an increase in $\mathrm{G}_{1} / \mathrm{S}$ ratio in $\mathrm{A} 549$ and $\mathrm{H} 1355$ cells treated with either MEK 
A549

\section{H1155}

\section{H1355}

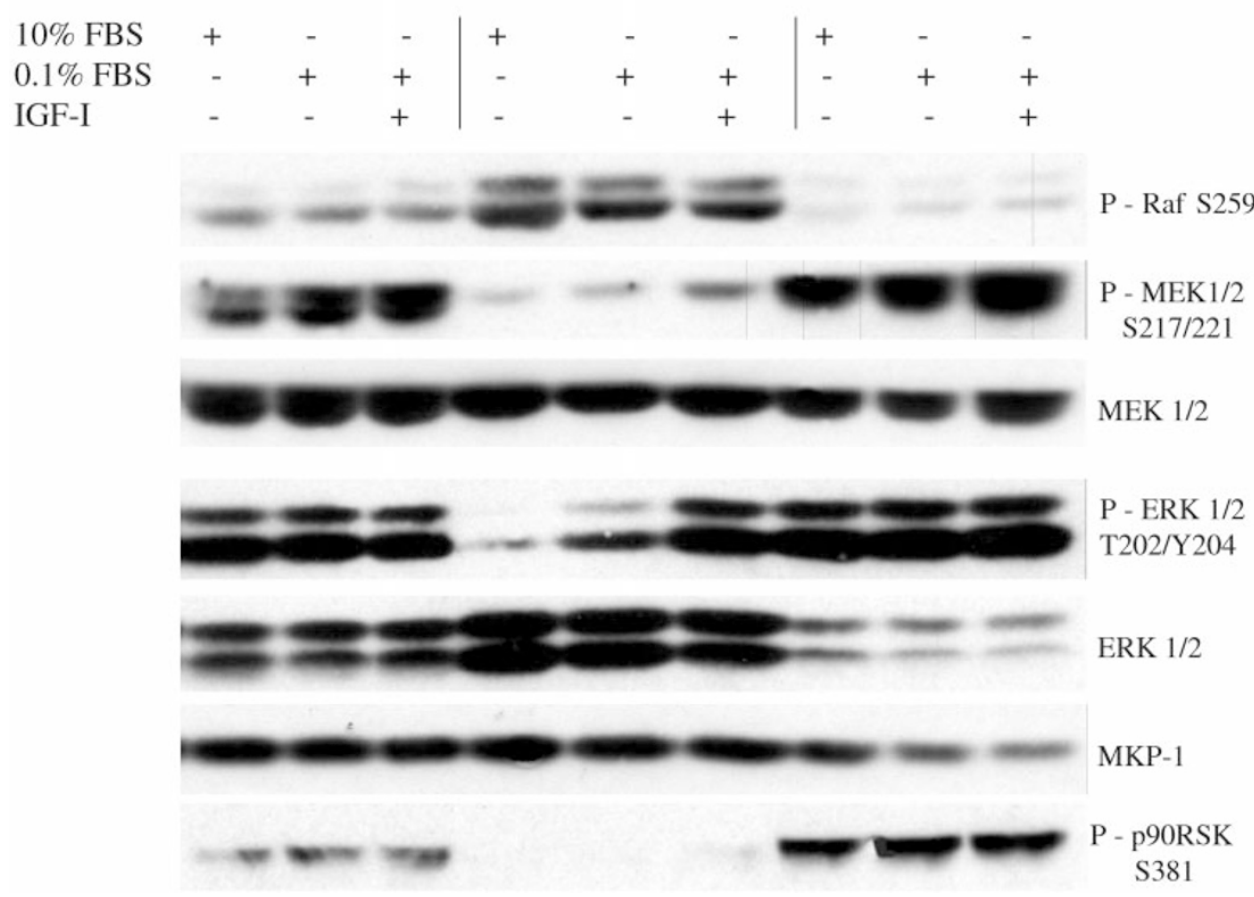

Figure 1 Immunoblot analysis of activation of the ERK pathway in three NSCLC cell lines. Cells were plated at $5 \times 10^{5} /$ well and media were changed to DMEM with $10 \%$ FBS or $0.1 \%$ FBS overnight. Some samples in $0.1 \%$ FBS were exposed to IGF-I ( $50 \mathrm{ng} / \mathrm{ml})$ stimulation for 10 min. Immunoblotting was performed as described utilizing native and phospho-specific antibodies. Equivalent protein was confirmed by staining membranes with fast green. ${ }^{32} \mathrm{~A}$ representative experiment from three independent experiments is shown

inhibitor. Patterns of cell cycle arrest were similar for both cell lines, with U0126 $(10 \mu \mathrm{M})$ being more potent than PD98059 $(25 \mu \mathrm{M})$. U0126 increased $\mathrm{G}_{1} / \mathrm{S}$ ratios from 5 to 23, and PD98059 increased $G_{1} / S$ ratios from 5 to 15 . U0126 slightly increased the $\mathrm{G}_{1} / \mathrm{S}$ ratio in $\mathrm{H} 1155$ cells, which have lower levels of ERK activity. Because the $\mathrm{G}_{1}$ to S-phase transition can be regulated by alterations in D-type cyclins, cyclin E, or the cdk inhibitors, p27 and p21, and because PD98059 has been shown to increase p27 levels in other systems, ${ }^{13,14}$ we measured levels of these cdk inhibitors and cyclins in NSCLC cells $48 \mathrm{~h}$ after the addition of PD98059 or U0126. Figure 2D, shows that PD98059 or U0126 increased p27 levels 7.5- and 9.9-fold, respectively, in A549 cells, but slightly decreased p21 levels. Similar results were obtained with the $\mathrm{H} 1355$ cells, where PD98059 and U0126 increased p27 levels 2.8- and 4.2fold, respectively, but greatly attenuated p21 levels. H1155 cells had no detectable p27 or p21 and the levels were not affected by MEK inhibition. MEK inhibitors also affected levels of D-type cyclins and cyclin $E$ in a cell line specific manner (Figure 2D). In A549 cells, PD98059 decreased levels of cyclins D1, D2 and E. U0126 had less of an effect on cyclins D1 and D2, but had a similar inhibition of cyclin E levels. In H1355 cells, PD98059 or U0126 increased cyclins D1 and D2, but decreased cyclin E levels. H1155 cells, which did not exhibit cell cycle arrest in response to MEK inhibitors, lacked cyclins D1 and D2 and MEK inhibitors had no effect on cyclin $E$ levels. With or without MEK inhibitor administration, cyclin D3 was undetectable in all three NSCLC cell lines (data not shown). These studies show that PD98059 or U0126 effectively inhibited the MEK/ ERK pathway, and caused $a \mathrm{G}_{0} / \mathrm{G}_{1}$ arrest in cells with high levels of ERK activity that correlated with induction of p27, but not p21. MEK inhibitor-induced increased levels of p27 correlated best with decreased cyclin E levels.

Because other investigators have observed apoptosis with administration of MEK inhibitors under normal growth conditions (reviewed $\mathrm{in}^{15}$ ), we analyzed apoptosis and cell cycle distribution in the three NSCLC cell lines after MEK inhibitor treatment for $48 \mathrm{~h}$ in $10 \%$ FBS. Figure 2E, shows that neither MEK inhibitor increased apoptosis in A549 or H1355 cells, but both MEK inhibitors increased apoptosis in $\mathrm{H} 1155$ cells. Basal levels of apoptosis were slightly higher in $10 \%$ FBS than $0.1 \%$ FBS, perhaps because of an artifact due to adherence of a small number of early apoptotic cells to the tissue culture plates throughout experiments performed in $10 \%$ FBS, which lead to their inclusion as apoptotic cells. In contrast, under conditions of $0.1 \%$ FBS, these apoptotic cells displayed greater loss of cellular architecture, detached more easily, and appeared to be lost or disintegrated during the course of processing and thus were not included in apoptotic measurements. Interestingly, little change in basal $\mathrm{G}_{1} / \mathrm{S}$ ratios was observed when NSCLC cells were grown in $0.1 \%$ or $10 \%$ FBS for $48 \mathrm{~h}$. (Figure 2 compare $\mathrm{C}$ and $\mathrm{F}$ ), which is consistent with our earlier observations, ${ }^{5}$ and the fact that p27 and p21 levels remained virtually constant when NSCLC cells were transitioned from normal growth to serum deprived condi- 
A

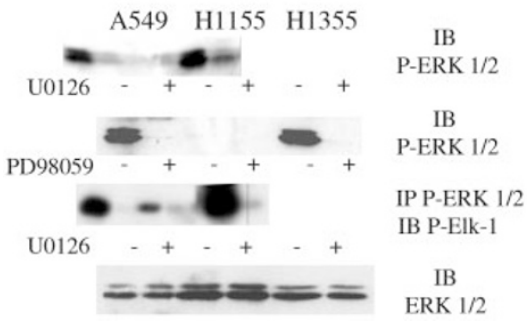

B

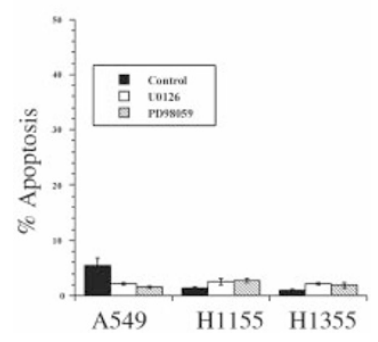

C

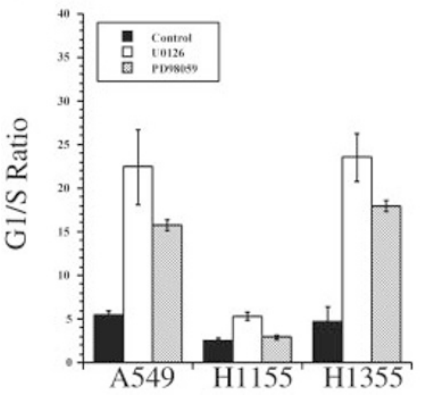

D

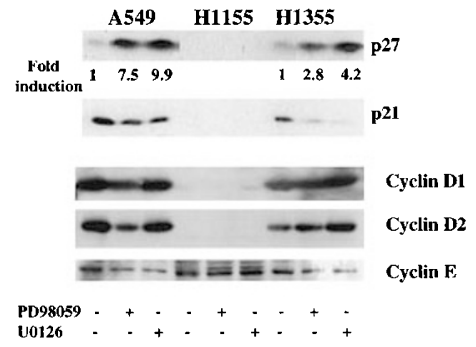

F

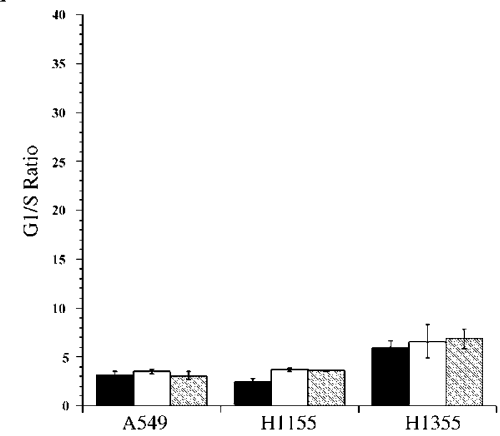

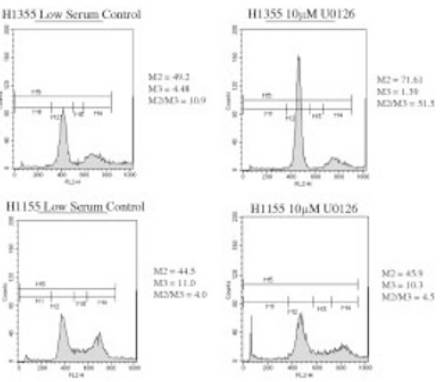

E

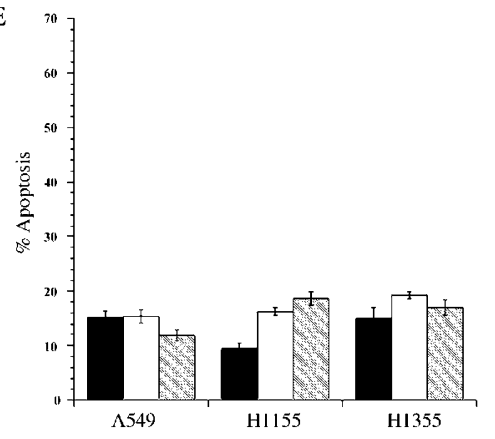

G

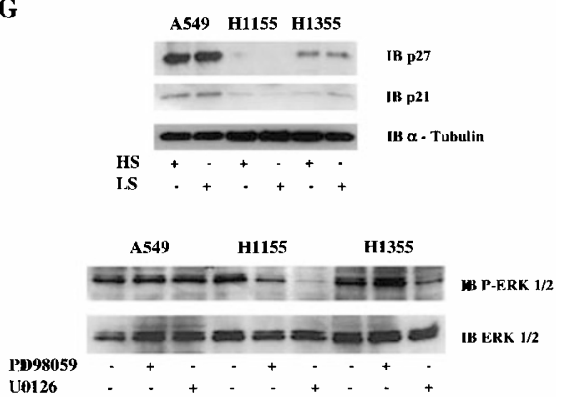

Figure 2 Effect of MEK inhibitors on ERK1/2 phosphorylation, kinase activity, and cell cycle distribution. (A) Cells were plated at $5 \times 10^{5} /$ well and were placed in $0.1 \%$ FBS media overnight. MEK inhibitors (PD98059 $(25 \mu \mathrm{M})$ or U0126 $(10 \mu \mathrm{M})$ ) were added $2 \mathrm{~h}$ prior to preparation of cell lysates for immunoblotting and kinase assays. Immunoblotting and kinase activity assays were performed as described. Levels of phosphorylated ERK1/2 and levels of phosphorylated Elk-1 at S383 after immunoprecipitation of active ERK are shown. A representative experiment from three independent experiments is shown. (B) Cells were plated at $1 \times 10^{5}$ cells/well and placed in $0.1 \%$ FBS media with or without MEK inhibitors for $48 \mathrm{~h}$. Cells were harvested and quantification of apoptosis by flow cytometry as described. Bars are the means \pm standard deviation of a representative experiment done in triplicate from three independently performed experiments. (C) Cells were prepared and treated as in B. Cell cycle distribution was determined and calculated using CellQuest software. Representative histograms used for calculations are shown. (D) Cells were incubated for $48 \mathrm{~h}$ in $0.1 \% \mathrm{FBS}$ with or without MEK inhibitors, and lysates were prepared for immunoblotting with antibodies directed against p21, p27, D-type cyclins, and cyclin E. Analysis of cell cycle (F) and apoptosis (E) was also performed in $10 \%$ FBS as described above. (G) shows immunoblotting for p27 and p21 after $48 \mathrm{~h}$ exposure to $10 \%$ FBS or $0.1 \%$ FBS (top) and immunoblotting for phosphorylated and native ERK after $48 \mathrm{~h}$ in $10 \%$ FBS (bottom). Quantification of band density was performed using NIH image software. Densitometry was performed over a range of exposures to ensure that relative differences in kinase activity were consistent. Immunoblotting was performed at least three times 
tions (Figure 2G). In contrast to the cytostatic effects of MEK inhibitors in A549 or H1355 cells under conditions of serum deprivation, neither MEK inhibitor increased $\mathrm{G}_{1} / \mathrm{S}$ ratios in these cells when they were grown in 10\% FBS. This was perhaps due to less effective inhibition of MEK by the MEK inhibitors in $10 \%$ FBS, as phosphorylation of ERK1/2 in A549 and $\mathrm{H} 1355$ cells was unchanged by the MEK inhibitors at $48 \mathrm{~h}$. (Figure 2G). H1155 cells, the only NSCLC cell line to undergo apoptosis in response to MEK inhibitors in $10 \% \mathrm{FBS}$, maintained inhibition of ERK phosphorylation at $48 \mathrm{~h}$. These studies show that the cytostatic effects of administering MEK inhibitors to NSCLC cells with high constitutive levels of ERK activity are dependent on conditions of serum deprivation, conditions where MEK inhibitors maintain inhibition of ERK activity. Whether higher doses of the MEK inhibitors or repeated dosing of the MEK inhibitors under normal growth conditions would result in inhibition of the MEK/ERK pathway and cell cycle arrest is unclear.

\section{Dominant negative mutants cause apoptosis without cell cycle arrest in NSCLC cells}

To confirm the cytostatic response of NSCLC cells to MEK inhibition by small molecule MEK inhibitors, we performed transient transfections with HA-epitope tagged, ATP-binding mutants of MEK (K97M) and ERK2 (K52R), and an activation mutant of ERK2 (TEYE). ${ }^{16}$ TEYE has glutamic acids substituted at T183 and Y185. Similar sites exist within the activation domain of ERK1 (T202 and Y204), where ERK1 and ERK2 are over $90 \%$ similar and the immediate surrounding amino acids are identical. Because activation of both ERK1 and ERK2 requires phosphorylation of these residues, TEYE is thought to behave as a dominant negative for both ERK1 and ERK2 (M Weber, M Cobb - personal communications). After transfection, expression of mutant proteins, cell cycle distribution, and apoptosis were assessed.

Figure $3 \mathrm{~A}$, left panels, shows expression of the three dominant negative constructs as assessed by immunoblotting whole cell extracts for the HA epitope tag. To determine the effects of the DNM constructs on cell cycle arrest and apoptosis, we co-transfected NSCLC cell lines with pCEP and GFP or HA-tagged DNMs and GFP and assessed apoptosis in the GFP-positive cells $48 \mathrm{~h}$ after recovery. Morphological changes characteristic of apoptosis including membrane blebbing, increased refractoriness, chromatin condensation, and cell shrinkage ${ }^{17}$ were evident at $48 \mathrm{~h}$. in NSCLC cells transfected with DNMs (data not shown). Figure $3 \mathrm{~B}$, shows that overexpression of the DNMs increased apoptosis in A549 and H1355 cells, which contain the highest levels of constitutively active ERK $1 / 2$. DNM ERK constructs were more effective than the DNM MEK (K97M) construct, and the greatest induction of apoptosis in the A549 cells was observed with the TEYE mutant. Basal levels of apoptosis in transfected H1155 cells were higher than in experiments with MEK inhibitors because of enhanced sensitivity to nonspecific toxic effects of the lipid transfection reagent with serum deprivation in these cells, ${ }^{5}$ and this precluded definitive evaluation of a dominant negative effect of these mutants. The lack of apoptosis observed with DNM MEK (K97M) in the A549 and $\mathrm{H} 1355$ cells is consistent with the lack of apoptosis observed with the MEK inhibitors, and suggests that inhibition of the ERK pathway at the level of MEK1/2 does not significantly alter survival of A549 or H1355 cells.

Because the DNM ERK constructs and small molecule MEK inhibitors had different effects on apoptosis, we analyzed cell cycle distribution in the transfected cells and found no increase in $G_{1} / S$ ratio with transfection of any of the DNMs (Figure $3 \mathrm{C}$ ). Although the percentage of surviving cells transfected with DNMs was decreased in every phase of the cell cycle, the greatest reductions were observed with cells in $\mathrm{G}_{0} / \mathrm{G}_{1}$ (see representative histogram of $\mathrm{H} 1355$ cells in Figure 3D). When p27 levels were measured in whole cell lysates (Figure 3E), transfection of DNMs did not increase p27 levels, even though p27 levels were nonspecifically increased over baseline in A549 cells. It is possible that p27 levels were increased in transfected cells, but because of the efficiency of transient transfection and possible dilutional effect of surrounding untransfected cells, these increases could not be detected. Together, these studies show that only DNMs (specifically K52R or TEYE) increased apoptosis without changing cell cycle distribution or increasing p27 levels.

\section{Dominant negative mutants, but not MEK inhibitors, increase chemotherapy-induced apoptosis in NSCLC cells}

Because our data with DNMs suggested that constitutive ERK activity contributes to NSCLC survival, we tested whether U0126 or TEYE would increase chemotherapy-induced apoptosis. U0126 and/or paclitaxel were added simultaneously and apoptosis was measured after $48 \mathrm{~h}$ of serum deprivation. Figure 4A, shows that U0126 alone had no effect in $\mathrm{H} 1355$ cells but slightly increased apoptosis in A549 and $\mathrm{H} 1155$ cells $(P<0.05)$. Paclitaxel alone increased apoptosis in all three cell lines, indicating that even with serum deprivation a sufficient number of cells were in $\mathrm{M}$ phase and able to undergo apoptosis in response to paclitaxel. When combined with paclitaxel in A549 and H1155 cells, U0126 did not potentiate paclitaxel-induced apoptosis $(P>0.05)$. In H1355 cells, U0126 attenuated paclitaxel-induced apoptosis $(P<0.05)$. This data contrasts with that of MacKeigan et al.., ${ }^{18}$ who showed that U0126 increased paclitaxel-induced apoptosis in a different NSCLC cell line (H157), but the potentiating effect of U0126 was dependent on induction of ERK phosphorylation by paclitaxel. In our studies, paclitaxel did not increase ERK phosphorylation (data not shown). Because the lack of effect of MEK inhibitors might be related to possible antagonism between U0126-induced $\mathrm{G}_{0} / \mathrm{G}_{1}$ arrest and paclitaxel-induced apoptosis in $M$ phase, we repeated these studies under normal growth (10\% FBS) conditions.

Figure 4B, shows that U0126 alone did not increase apoptosis in A549 or H1355 cells, but increased apoptosis in the $\mathrm{H} 1155$ cells. The addition of paclitaxel alone to the three NSCLC cell lines in 10\% FBS caused greater apoptosis than that observed in $0.1 \%$ (Figure $4 \mathrm{~A}$ ), suggesting that more cells are in M-phase in 10\% FBS 
and thus susceptible to paclitaxel. When added simultaneously with paclitaxel, U0126 antagonized the effects of paclitaxel in A549 and $\mathrm{H} 1155$ cells, and had no effect in H1355 cells. Therefore, these studies show that antagon- ism between MEK inhibitors and paclitaxel is greatest under normal growth conditions.

To confirm the effects of U0126 on chemotherapyinduced apoptosis, we performed similar studies using
A

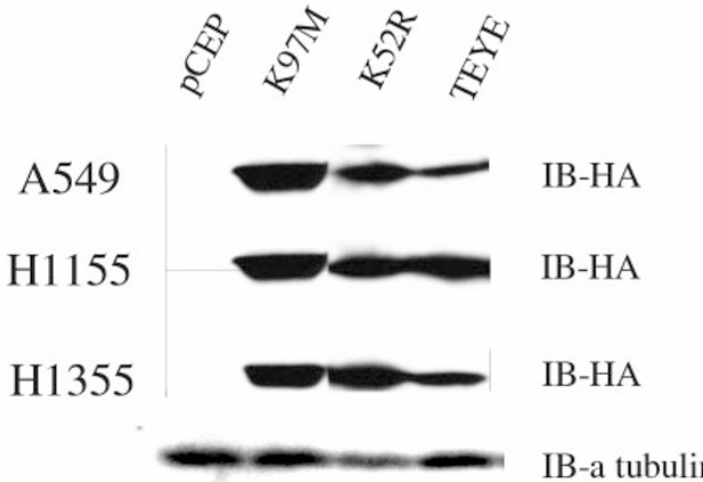

C

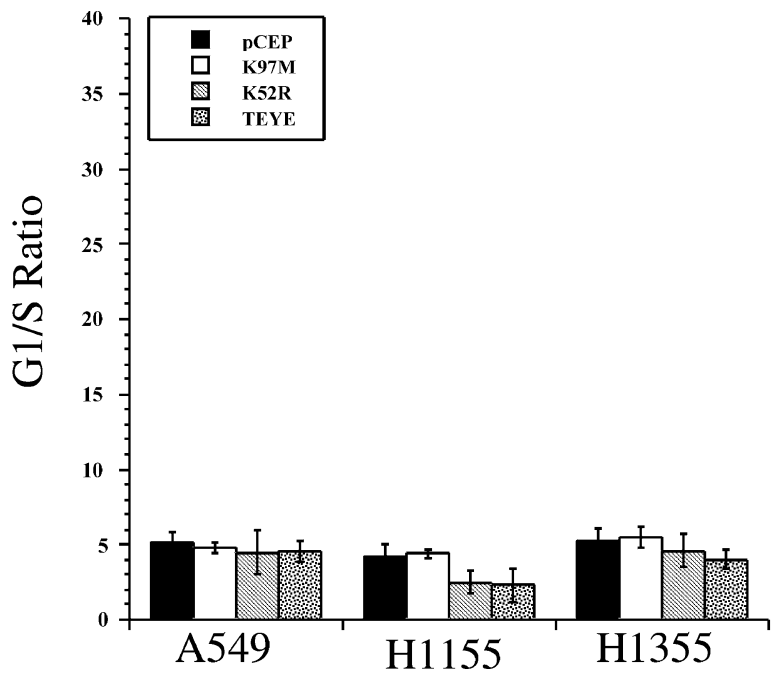

B

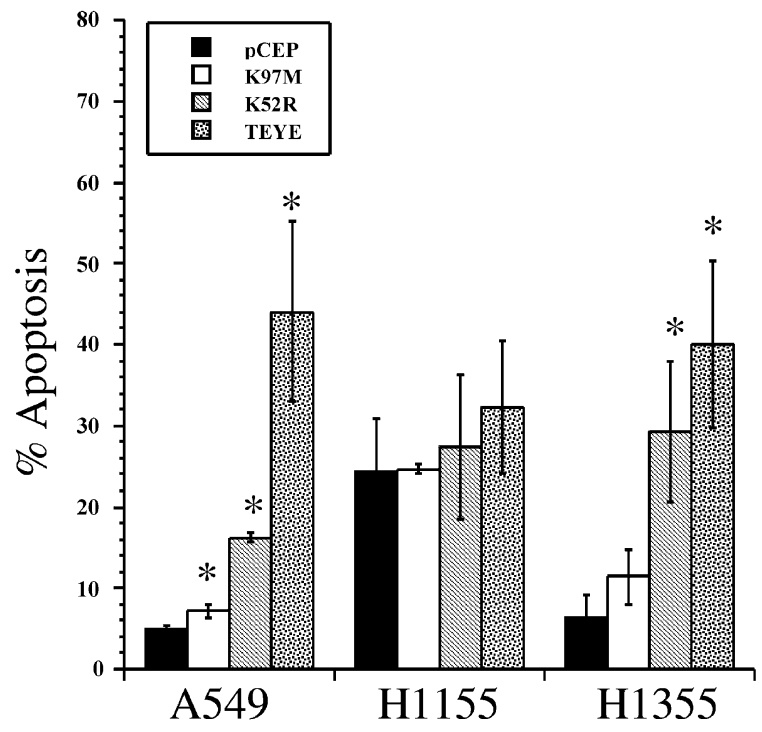

$\mathrm{D}$
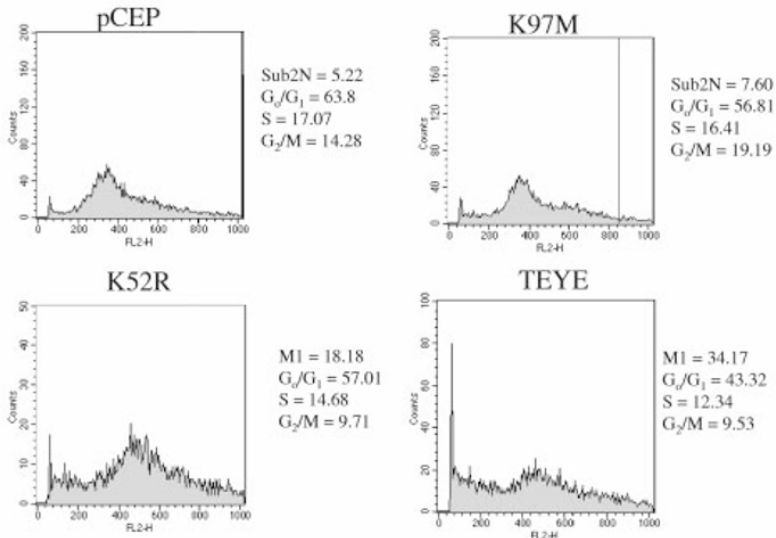

TEYE

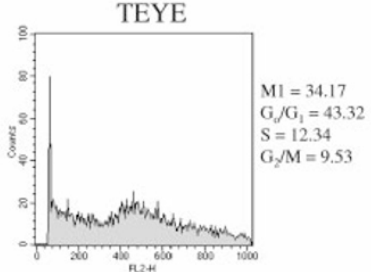

E

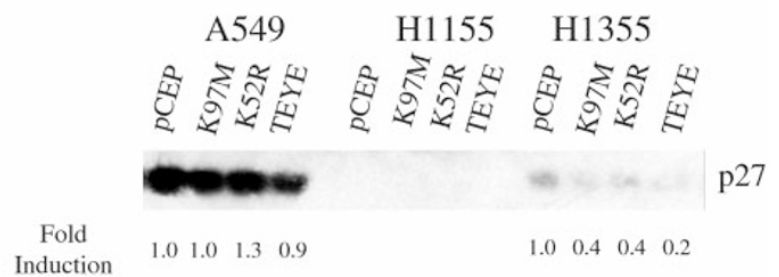

Figure 3 Expression of DNMs and effects on apoptosis, and cell cycle distribution. (A) Cells were plated at $2 \times 10^{5} /$ well and samples were transiently cotransfected with plasmids encoding GFP and PCEP, GFP and K97M, GFP and K52R, or GFP and TEYE as described. HA expression was assessed by immunoblotting. (B and C) Cells were transiently co-transfected as above with plasmids encoding GFP and pCEP (black bars), GFP and K97M (white bars), GFP and K52R (striped bars) or GFP and TEYE (dotted bars) as described. Cells were allowed to recover from transfection for $24 \mathrm{~h}$, then exposed to $0.1 \%$ FBS for $48 \mathrm{~h}$. Samples were fixed, stained with propidium iodide, and prepared for flow cytometry. Apoptosis was quantified by gating on GFP positive cells and performing cell cycle analysis $(B) . G_{1} / S$ ratios $(C)$ and a representative histogram of gated $A 549$ cells showing cell cycle distribution are shown in (D and $\left.E\right)$. Parallel samples were also harvested for immunoblotting with anti-p27 antibodies. Quantification of band density was performed using NIH Image software. A representative experiment from three independent experiments performed with each cell line is shown 
DNM TEYE. pCEP and GFP or TEYE and GFP were transiently co-transfected into $\mathrm{H} 1355$ and $\mathrm{H} 1155$ cells and apoptosis was assessed in the GFP positive cells at $72 \mathrm{~h}$ (48 $\mathrm{h}$ after serum deprivation and/or paclitaxel exposure). Figure 4C, shows that transfection of TEYE into $\mathrm{H} 1355$ cells increased basal levels of apoptosis from 6 to $34 \%$, compared to vector alone. Combining TEYE and paclitaxel appeared greater than additive in potentiating apoptosis in the $\mathrm{H} 1355$ cells, which is remarkable because of the antagonism observed with U0126 and paclitaxel. Levels of apoptosis were less with paclitaxel treatment of pCEPtransfected cells compared with untransfected cells (Figure $4 \mathrm{~A})$, because gating on GFP-positive cells eliminated untransfected, apoptotic cells from being included in the apoptotic measurement. In fact, the amount of apoptosis in paclitaxel-treated, GFP-negative control transfectants was similar to that of paclitaxel-treated, untransfected cells (data not shown). Similar results were obtained from transient transfection experiments performed in A549 cells (data not shown). Because basal levels of apoptosis in H1155 cells were again higher in these experiments because of nonspecific toxic effects of the lipid transfection reagent, it was difficult to assess whether TEYE affected basal- or paclitaxel-induced apoptosis in $\mathrm{H} 1155$ cells. Nonetheless, these results are similar to the divergent apoptotic responses observed with MEK inhibitors and DNMs in cells with high levels of active ERK. Namely, inhibition of ERK by TEYE, but not U0126, increased chemotherapyinduced apoptosis. We then repeated these transient transfection studies under normal growth conditions $(10 \%$ FBS).

Figure 4D, shows that in $\mathrm{H} 1155$ cells transfected with pCEP, levels of apoptosis were lower in 10\% FBS than under conditions of serum deprivation (Figure $3 C$ ). With decreased levels of apoptosis with transfection of pCEP under normal growth conditions, an increase in TEYEinduced apoptosis could be observed in $\mathrm{H} 1155$ cells. Levels of apoptosis induced by paclitaxel were not affected by transfection of TEYE, suggesting that ERK inhibition by TEYE may not have been as effectively sustained in $10 \%$ FBS (similar to the inhibition of ERK activity by MEK inhibitors in $10 \% \mathrm{FBS}$ ), or that ERK activity was not necessary for survival in 10\% FBS because other prosurvival signaling pathways were activated by $10 \%$ FBS. In $\mathrm{H} 1355$ cells, transfection of TEYE increased apoptosis, but levels of apoptosis were lower than those observed under conditions of serum deprivation. In addition, TEYE did not affect paclitaxel-induced apoptosis, again suggesting less effective ERK inhibition or activation of ERK-independent survival pathways by $10 \%$ FBS.

When combined with results from experiments performed under conditions of serum deprivation, these studies show that transfection of TEYE increased basal levels of NSCLC cell apoptosis in 0.1 or $10 \%$ FBS in cells with the highest levels of constitutive ERK activity, but that likely due to an artifact, TEYE-induced apoptosis in $\mathrm{H} 1155$ cells was only evident in $10 \%$ FBS. The effects of transfecting TEYE on basal- and paclitaxel-induced apoptosis were greater in 0.1 than $10 \%$ FBS, probably because ERK inhibition was sustained under conditions of serum deprivation. Because only approximately $5 \%$ of cells in solid tumors synthesize DNA at any given time, ${ }^{19}$ and because the percentage of NSCLC cells in S-phase with serum deprivation in our studies was 5-10\% (data not shown), we believe that the results obtained with TEYE under conditions of serum deprivation may be more physiologically relevant than the results obtained with $10 \%$ FBS, where typically greater than $10 \%$ of NSCLC cells were in S-phase (data not shown). Therefore, these studies with TEYE suggest that ERK activity might promote both cellular survival and chemotherapeutic resistance of NSCLC cells.

\section{Discussion}

Our studies have identified constitutive ERK activity in $89 \%$ $(17 / 19)$ of NSCLC cell lines. Previously, Hoshino et $a l^{2}$ had showed that ERK activity was increased in 8/21 (38\%) of lung cancer cell lines, but the majority of the cell lines analyzed were small cell lung cancer cell lines. Thus, our study is the largest analysis of ERK activity in NSCLC cells to date. ERK activity did not correlate with NSCLC histology or mutations in $\mathrm{p} 53, \mathrm{Rb}$, or K-ras, and the mechanism of increased ERK activation is unknown. Detailed analyses of three NSCLC cell lines demonstrated increased phosphorylation of multiple components in the pathway, including MEK1/2, ERK1/2 and p90RSK in A549 and $\mathrm{H} 1355$ cells compared to $\mathrm{H} 1155$ cells. In contrast, $\mathrm{H} 1155$ cells displayed high endogenous Akt activity, whereas A549 and H1355 cells exhibited low Akt activity. ${ }^{5}$ This implies a potential inverse relationship between endogenous Akt and ERK activities. Whether this inverse relationship between ERK and Akt is widely applicable is unclear. Current studies are addressing mechanisms of regulation between these pathways in NSCLC cells.

Perhaps the most interesting result of these studies is the divergent cellular responses of NSCLC cells to administration of small molecule MEK inhibitors or transient transfection of DNMs. Both MEK inhibitors, PD98059 and U0126, inhibited ERK phosphorylation and activity, and in A549 and $\mathrm{H} 1355$ cells (which have the highest levels of ERK activity) caused a cell cycle arrest in $G_{0} / G_{1}$ that correlated with increased p27 levels and decreased levels of cyclin E. No effects on apoptosis were observed. In contrast, DNMs potentiated apoptosis in A549 and H1355 cells without altering cell cycle distribution. Contrasting cellular responses to inhibition of the MEK/ERK pathway in A549 and H1355 cells were observed under both normal growth conditions and conditions of serum deprivation.

Divergent responses were not as apparent in $\mathrm{H} 1155$ cells that had lower levels of constitutive ERK activity. The MEK inhibitors increased apoptosis slightly in serum deprivation, but increased apoptosis significantly under normal growth conditions. Due to nonspecific toxic effects of transient transfection under conditions of serum deprivation, effects of DNMs in $\mathrm{H} 1155$ cells could not be assessed. Under normal growth conditions, however, DNM ERK2 increased apoptosis. Therefore, divergent responses could not be assessed in serum deprivation, but increases in apoptosis in response to both modes of ERK inhibition were observed under normal growth conditions. 
A

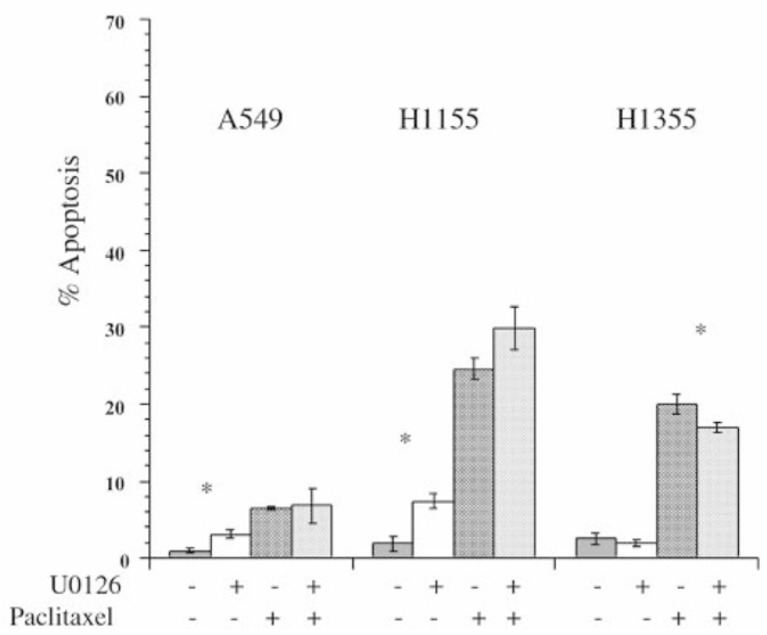

C

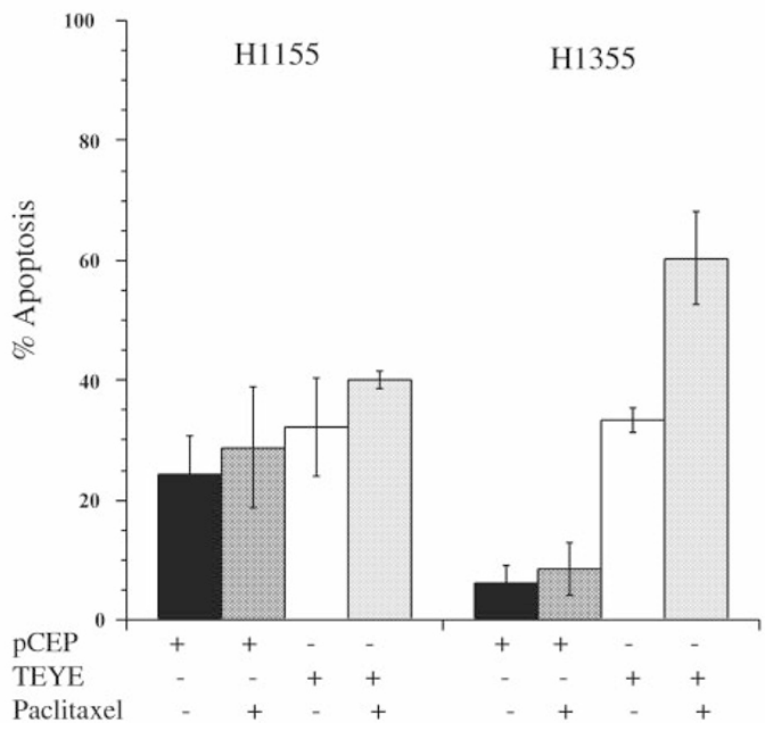

B

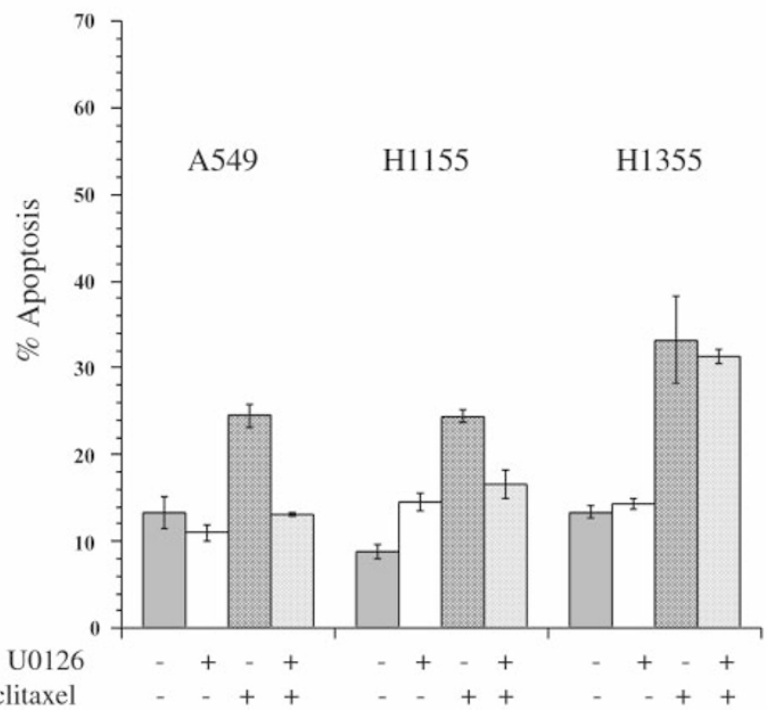

D

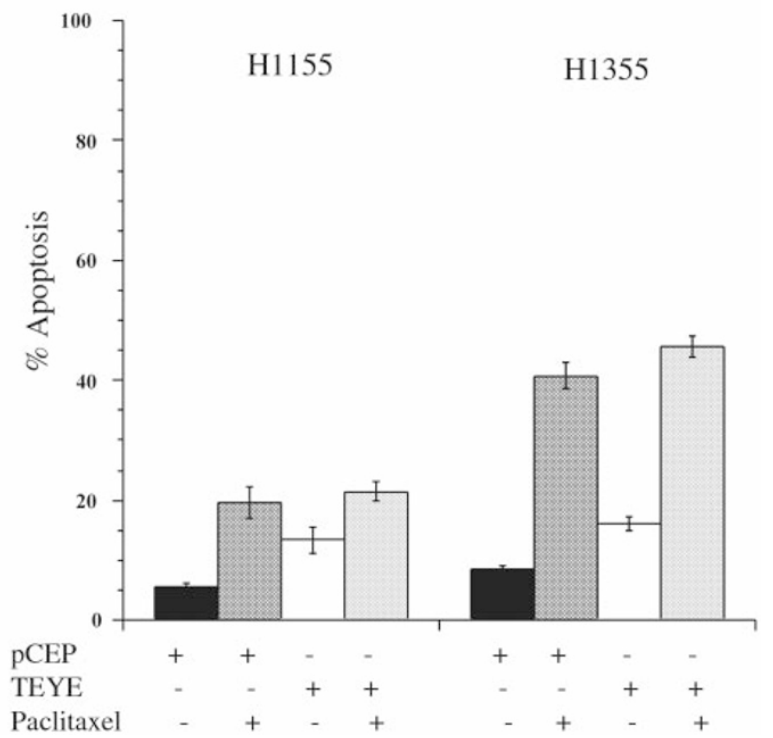

Figure 4 Effect of U0126 and TEYE on chemotherapy-induced apoptosis. (A) U 0126 cells were plated at $1 \times 10^{5} /$ well and placed in $0.1 \%$ FBS. U0126 ( $\left.10 \mu \mathrm{M}\right)$ and paclitaxel $(5 \mu \mathrm{M})$ were added simultaneously and cells were incubated for $48 \mathrm{~h}$. Apoptosis was quantified as described. Bars are the means + standard deviation of a representative experiment done in triplicate from three independently performed experiments. (B) Shows the same experiments performed in $10 \%$ FBS. (C) TEYE cells were plated with at $2 \times 10^{5}$ well and transiently co-transfected with plasmids encoding GFP and pCEP(darker bars) or GFP and TEYE (lighter bars) as described. Cells were allowed to recover from transfection for $24 \mathrm{~h}$, then exposed to $0.1 \%$ FBS with (stippled bars) or without (solid bars) paclitaxel for an additional $48 \mathrm{~h}$. Samples were fixed, stained with propidium iodide, and prepared for flow cytometry. Apoptosis was quantified by gating on GFP positive cells and performing cell cycle analysis. Bars are the means \pm standard deviation of a representative experiment done in triplicate from three independently performed experiments. (D) Shows the same experiments performed in $10 \%$ FBS

Because these divergent responses have not been described previously, we performed experiments to demonstrate that the apoptotic effects of the DNMs were not artifactual. First, was potentiation of apoptosis by DNMs a nonspecific effect due to dependence on ERK activity for survival after transient transfection? To ensure that blocking the MEK/ERK pathway in cells undergoing transfection would not nonspecifically increase apoptosis, we trans- fected H1355 cells with pCEP and GFP, treated with PD98059, and assessed apoptosis in GFP-positive cells. ERK activity was inhibited by PD98059, but no increase in apoptosis was observed (data not shown). These data indicate that cellular survival after transient transfection does not depend on ERK activity. Second, because pCEP is an episomal vector, will overexpression of any exogenous protein cause apoptosis of NSCLC cells? Arguments 
against this point include the expression of DNM MEK (Figure 3) and GFP (see above) without consequent increases in apoptosis. In addition, we performed transient transfections using wild-type ERK2 as a control instead of pCEP. When $\mathrm{H} 1355$ cells were transfected with wild-type ERK2 and GFP or TEYE and GFP, apoptosis was only observed in the GFP-positive cells transfected with TEYE (data not shown).

The divergent cellular responses we observed with administration of MEK inhibitors or transfection of DNMs appear to contrast with data from other investigators, especially that of Hoshino et al. ${ }^{14}$ Important distinctions between these two sets of studies may explain the varying biologic responses. First, Hoshino et al. ${ }^{14}$ used higher doses of PD98059 $(50 \mu \mathrm{M})$ and U0126 $(20 \mu \mathrm{M})$ to inhibit ERK activity and induce apoptosis. These concentrations are rarely used to inhibit ERK activity in vitro, and increase the likelihood of non-specific effects of these compounds. Second, although an increase in cell cycle arrest at $G_{0} / G_{1}$ was observed within $24 \mathrm{~h}$ in cells that eventually underwent apoptosis in response to PD98059, apoptosis was not observed until $96 \mathrm{~h}$, suggesting an indirect potentiation of apoptosis by PD98059. When we treated the NSCLC cell lines used in our studies with PD98059 or U0126 for $96 \mathrm{~h}$ under conditions of serum deprivation, inhibition of ERK phosphorylation and cell cycle arrest were maintained without an increase in apoptosis (data not shown). Interestingly, in both studies PD98059 induced $G_{0} / G_{1}$ cell cycle arrest that was associated with a selective increase in p27 levels. Third, Hoshino et al. ${ }^{14}$ used a different DNM construct (a phosphorylation mutant (MEK-AA) rather than the K97M ATP binding mutant) to confirm results with PD98059. Fourth, induction of p27 by MEK-AA was only measured in one field of transfected cells using immunofluorescent techniques. Most importantly, apoptotic effects of DNM MEK-AA were not assessed. If apoptosis with the MEK-AA mutant would have been assessed and not observed, and if the apoptotic effects of PD98059 were either nonspecific or indirect, then the results of the two studies would be quite similar, in spite of the use of different cell lines.

Assuming our data do not result from experimental artifacts, what is the biochemical basis for these differing cellular responses? One possibility is that ERK is simply a better target to inhibit than MEK to induce NSCLC cell apoptosis. While comparison of apoptosis induced by DNM MEK with DNM ERK2 suggests that ERK is a better target, two findings from our studies also support MEK as a putative therapeutic target. First, although DNM MEK did induce less apoptosis than DNM ERK2 constructs in the A549 and H1355 cells, a small amount of apoptosis was observed with $\mathrm{K} 97 \mathrm{M}$ in A549 cells, whereas none was observed with PD98059 or U0126. Second, H1155 cells, unlike A549 and H1355 cells, underwent apoptosis in response to MEK inhibitors in both normal growth conditions and conditions of serum deprivation. Therefore, the lack of apoptosis with MEK inhibitors and the lack of a robust response to DNM MEK in A549 and H1355 cells was probably not due to choice of MEK itself as a target.
Our studies showed that the best biochemical correlate of response to MEK inhibitors or DNMs and cellular response was induction of the cdk inhibitor, p27. A549 and H1355 cells induced p27 in response to the MEK inhibitors and survived, whereas $\mathrm{H} 1155$ cells, which did not express p27 nor induce p27, underwent apoptosis in response to the MEK inhibitors (greatest response observed under normal growth conditions). None of the DNMs increased p27 levels, in spite of increased apoptosis in the A549 and H1355 cells (response of H1155 cells in serum deprivation could not be adequately assessed). These studies suggest that any mode of inhibition of the MEK/ ERK might result in an apoptotic response in NSCLC cells as long as p27 is not induced, and that the divergent responses in our studies were not due to differences in method of inhibition of the pathway, but rather differences in induction of p27. Other investigators have shown that $\mathrm{PD} 8059^{13}$ or $\mathrm{U} 0126^{20}$ can increase p27 levels by inhibiting protein degradation, but the mechanism by which MEK inhibitors increased p27 in our studies is unclear. Definitive attribution of NSCLC cell survival after MEK inhibition to p27 induction will require the manipulation of p27 levels with genetic approaches and assessing the cellular responses to MEK inhibition by different modalities. Interestingly, the potential role of p27 in mediating survival after inhibition of the MEK/ERK pathway was derived from contrasting responses of the $\mathrm{H} 1155$ cells that lacked p27 under our experimental conditions with the A549 and $\mathrm{H} 1355$ cells. Of note, the $\mathrm{H} 1155$ cells are also the only NSCLC cell line of the three that has mutant Rb, which raises the possibility that $\mathrm{Rb}$ status may control the cellular response to MEK inhibition.

Another difference between MEK inhibitors and DNMs might be related to greater specificity offered by DNMs. In addition to inhibiting MEK1/2, PD98059 and U0126 also inhibit MEK5, which activates ERK5, a recently described member of the MAPK family. ${ }^{21,22}$ Although it is unclear if the ERK DNMs used in these studies (K52R and TEYE) inhibited ERK5 activity, K97M does not inhibit MEK5 activity (N Ahn, personal communication), and a different ERK2 DNM (T183A and Y185F) did not inhibit ERK5 activity. ${ }^{23}$ Whether differences in ERK5 inhibition in concert with ERK1/2 inhibition explain the differences in cellular responses awaits further study. DNMs may offer greater specificity because MEK inhibitors may also inhibit enzymes outside the MAPK family. Although there are no published data on effects of U0126 on substrates outside the MAPK family, PD98059 has equipotent effects on inhibiting MEK, cyclooxygenase (COX) 1 and 2, and the aryl hydrocarbon receptor. ${ }^{24,25}$ Inhibition of COX-2 by MEK inhibitors is unlikely to explain the cytostatic effects of the MEK inhibitors, however, because other investigators have shown that COX-2 inhibitors are cytotoxic to NSCLC cells, with and without chemotherapy. ${ }^{26,27}$ In contrast to PD98059, nonspecific effects of DNMs toward inhibition of other targets have not been described. Future studies will determine if DNMs and small molecule MEK inhibitors have differential effects on inhibition of COX-1, COX-2, or aryl hydrocarbon receptors, and whether this contributes to the 
different cellular responses of NSCLC cells to inhibition of the MEK/ERK pathway by MEK inhibitors or DNMs.

Combining MEK inhibitors or DNMs with chemotherapy also led to different cellular responses. These differences were most apparent under conditions of serum deprivation. In $0.1 \%$ FBS, U0126 did not increase paclitaxel-induced apoptosis in A549 or $\mathrm{H} 1155$ cells, and attenuated paclitaxel-induced apoptosis in $\mathrm{H} 1355$ cells. In contrast, TEYE had a greater than additive effect on potentiating paclitaxel-induced apoptosis in $\mathrm{H} 1355$ cells. Under normal growth conditions, U0126 attenuated paclitaxel-induced apoptosis in all three NSCLC cell lines. Although TEYE did not increase paclitaxel-induced apoptosis in 10\% FBS, no attenuation of the levels of apoptosis in cells transfected with pCEP exposed to paclitaxel was observed. These studies suggested that cell cycle antagonism might have lowered the sensitivity of NSCLC cells to combinations of paclitaxel and MEK inhibitors, and that activation of other signaling pathways in $10 \%$ FBS might have diminished the importance of ERK inhibition.

To test the combination of MEK inhibitors with chemotherapy without the potential confounding issue of cell cycle antagonism, we added MEK inhibitors to cell cycle-independent chemotherapies such as etoposide or cisplatin in NSCLC cells and measured apoptosis. Similar results were obtained, in that MEK inhibitors did not increase chemotherapy-induced apoptosis (data not shown). Moreover, we did not detect a sequence dependence of MEK inhibitors ${ }^{28}$ with any form of chemotherapy tested when MEK inhibitors were added before, after, or simultaneously with chemotherapy (data not shown). Likewise, we doubt that differences in timing of ERK inhibition by U0126 or TEYE explain the differential sensitivity to paclitaxel. Although experiments with TEYE were designed to allow $24 \mathrm{~h}$ for expression (and thus hypothetical ERK inhibition) prior to addition of paclitaxel, no increase in apoptosis was observed when PD98059 or U0126 was added $24 \mathrm{~h}$ prior to chemotherapy (data not shown).

Cellular responses to combining MEK inhibitors with paclitaxel are likely cell type specific. Other investigators have shown that MEK inhibitors protect cells from paclitaxel-induced apoptosis in leukemic, neuroblastoma and esophageal carcinoma cells. ${ }^{29-31}$ The biochemical basis for this protection is not clear. Cell type specificity may reflect differential inhibition of downstream ERK substrates or varying effects of MEK inhibitors on other molecules such as cdk inhibitors, COX-1, COX-2, or aryl hydrocarbon receptors that may independently affect chemotherapy-induced apoptosis.

Our data support the hypothesis that targeting the MEK/ ERK pathway may have therapeutic value in cancer therapy because NSCLC cells with constitutive ERK activity underwent apoptosis in response to inhibition of the MEK/ ERK pathway. However, this is the first report demonstrating a discrepancy in cellular response using small molecule inhibitors or DNMs, the two most commonly employed methods to inhibit signal transduction pathways such as the MEK/ERK pathway. There are practical implications of these findings. First, the use of MEK inhibitors alone may provide misleading results. Many investigators have utilized MEK inhibitors without DNMs to infer involvement of ERK activity in biologic processes. Balliff and Blenis ${ }^{15}$ recently reviewed all published studies investigating the MEK/ERK pathway in cellular survival and found that only $9 / 79(11 \%)$ confirmed results obtained with MEK inhibitors with DNMs. Although PD98059 and U0126 effectively inhibit ERK activity, they have pleotropic effects within cells and any attribution to ERK activity by use of MEK inhibitors should be confirmed with DNMs or other genetic approaches if possible. Secondly, the induction of apoptosis by DNMs with and without chemotherapy suggests that targeting the ERK pathway might eventually have therapeutic benefit for patients with NSCLC. Phase I clinical trials with small molecule MEK inhibitors are planned, but hopes for cytotoxic responses or tumor reduction have been tempered by the cytostatic effects of newer MEK inhibitors in vivo. ${ }^{3}$ Accepting cytostatic responses as a best response to inhibition of the ERK pathway may be premature and defeatist, however, and may reflect a lack of understanding of the basis for the differing cellular responses to ERK inhibition by small molecules or DNMs. Identifying the molecular mechanisms responsible for cytostatic responses might suggest a combination of approaches (e.g., MEK inhibition with p27 inhibition) that could convert a cytostatic response to a cytotoxic response, thereby mimicking the effects of DNMs and increasing therapeutic efficacy.

\section{Materials and Methods}

\section{Materials}

U0126, PD98059, and paclitaxel were from CalBiochem (La Jolla, CA, USA). Anti-Raf, MEK1/2, ERK1/2, and p90RSK antibodies and the ERK $1 / 2$ kinase assay kit were from New England Biolabs (Beverly, MA, USA). HA-probe F7, MKP-1, p21, p27, cyclins D and cyclin E antibodies were from Santa Cruz Biotechnology Inc. (Santa Cruz, CA, USA). Protease inhibitor cocktail was obtained from Sigma, and protein assay materials were from Biorad (Hercules, CA, USA.) All cell culture reagents were purchased from Life Technologies (Rockville, $M D, U S A)$. Protran pure nitrocellulose membranes were purchased from Schleicher \& Schulell (Dassel, Germany). Plasmid pEGFP-F was purchased from Clontech (Palo Alto, CA, USA). pCEP, K79M (a MEK1/ 2 ATP binding mutant), TEYE (with glutamic acids substituted at T183 and Y185), and K52R (an ERK2 ATP binding mutant) plasmids ${ }^{16}$ were generously donated by Melanie Cobb, University of Texas Southwestern Medical Center, Dallas, TX, USA.

\section{Cell culture}

All NSCLC lines were provided by H Oie or F Kaye at National Cancer Institute/Naval Medical Oncology. All cell lines were maintained in $75 \mathrm{~cm}^{2}$ flask in DMEM supplemented with $10 \%$ FBS, $100 \mathrm{U} / \mathrm{ml}$ penicillin, and $100 \mu \mathrm{g} / \mathrm{ml}$ streptomycin.

\section{Transient transfections}

Cells were plated at $60 \%$ confluency and transfected using Superfect transfection reagent according to the manufacturer's protocol (Quiagen Valencia, CA, USA). Plasmids encoding pCEP, K97M, 
TEYE, and K52R were co-transfected with pEGFP-F. Transfection efficiency ranged from $30-70 \%$. Only cells expressing GFP were analyzed by flow cytometry. Parallel samples were harvested for immunoblotting, kinase assays, and flow cytometry in each experiment. Transfection efficiency ranged from $20-50 \%$. Experiments were repeated at least three times.

\section{Pharmacologic treatments}

NSCLC cells were plated at $2-4 \times 10^{5}$ cells per well. After attachment, the media was changed to DMEM with $10 \%$ or $0.1 \%$ FBS and the cells were incubated overnight. U0126 $(10 \mu \mathrm{M})$ or PD98059 $(25 \mu \mathrm{M})$ was added $2 \mathrm{~h}$ prior to lysing the cells for immunoblotting. To study the effects of PD98059 and U0126 on apoptosis, cells were incubated in $0.1 \%$ FBS DMEM in the absence or presence of the inhibitor for $48 \mathrm{~h}$. For combination experiments, either U0126 or PD98059 was added simultaneously with paclitaxel and both were incubated for $48 \mathrm{~h}$ prior to quantification of apoptosis. For experiments with transiently transfected cells, paclitaxel was added $48 \mathrm{~h}$ prior to immunoblotting or flow cytometry analysis.

\section{Immunoblot analysis}

Preparation of cell extracts, protein assays, and immunoblotting were performed as previously described. ${ }^{5}$

\section{In vitro kinase assays}

ERK $1 / 2$ kinase assays were performed as recommended by New England Biolabs, with minor modifications. Cells were plated at a concentration of $2-4 \times 10^{5}$. Cells were then washed $1 \times$ with ice-cold PBS and $200 \mu$ of ice-cold lysis buffer supplemented with $1 \mathrm{mM} \mathrm{PMSF}$ was added to the cells and incubated for $10 \mathrm{~min}$. Lysates were sonicated, cleared and allowed to immunoprecipitate overnight at $4{ }^{\circ} \mathrm{C}$ with anti-phospho-ERK1/2 antibody. Immunoprecipitates were washed twice with lysis buffer and twice with kinase buffer that were supplied with the kit. Kinase reactions were performed for $30 \mathrm{~min}$ at $30^{\circ} \mathrm{C}$ in kinase buffer supplemented with $200 \mu \mathrm{M}$ ATP and $1 \mu \mathrm{g}$ ELK-1 fusion protein. Reaction was terminated with $3 \times$ SDS buffer, heated for $5 \mathrm{~min}$, and loaded into a $12 \%$ acrylamide gel. After transfer to nitrocellulose membranes, immunoblotting for phospho-ELK-1 was performed using phospho-specific ELK-1 antibodies as provided in the ERK $1 / 2$ kinase assay kits. Quantification of band density was performed using NIH Image software. Densitometry was performed over a range of exposures to ensure that relative differences in kinase activity were consistent.

\section{Apoptosis assays}

Floating and adherent cells were harvested, fixed in $70 \%$ methanol added dropwise, and incubated at $-20^{\circ} \mathrm{C}$ for $30 \mathrm{~min}$. Cells were then centrifuged and incubated with propidium iodide $(25 \mu \mathrm{g} / \mathrm{ml})$ supplemented with RNase A $(30 \mu \mathrm{g} / \mathrm{ml})$ for $30 \mathrm{~min}$ at room temperature. Quantification of sub-2N DNA was determined by flow cytometry using a Becton-Dickinson FACSort.

\section{Acknowledgments}

We gratefully acknowledge Steven Shein for his assistance in this project, and Drs A Fojo and $\mathrm{K}$ West for helpful criticism of the manuscript.

\section{References}

1. Cobb MH (1999) MAP kinase pathways. Prog. Biophys. Mol. Biol. 71: 479-500

2. Hoshino R, Chatani Y, Yamori T, Tsuruo T, Oka H, Yoshida O, Shimada Y, Ari-iS, Wada H, Fujimoto Jand Kohno M (1999) Constitutive activation of the 41-/43-kDa mitogen-activated protein kinase signaling pathway in human tumors. Oncogene 18: $813-822$

3. Sebolt-Leopold JS, Dudley DT, Herrera R, Van Becelaere K, Wiland A, Gowan RC, Tecle H, BarrettSD, Bridges A, Przybranowski S, Leopold WR and Saltiel AR (1999) Blockade of the MAP kinase pathway suppresses growth of colon tumors in vivo (see comments). Nat. Med. 5: 810-816

4. Landis SH, Murray T, Bolden Sand Wingo PA (1999) Cancer statistics, 1999 (see comments). CA Cancer J. Clin. 49: 8-31, 31

5. Brognard J, Clark AS, Ni Y and Dennis PA (2001) Akt/protein kinase $b$ is constitutively active in non-small cell lung cancer cells and promotes cellular survival and resistance to chemotherapy and radiation. Cancer Res. 61: $3986-$ 3997

6. Oie HK, Russell EK, Carney DN and Gazar AF (1996) Cell Culture Methods for the Establishment of the NCI Series of Lung Cancer Cell Lines. J. Cell. Biochem. Suppl. 24: 24-31

7. Bonni A, BrunetA, West AE, Datta SR, Takasu MAand Greenberg ME (1999) Cell survival promoted by the Ras-MAPK signaling pathway by transcriptiondependent and -independent mechanisms (see comments). Science 286: $1358-1362$

8. Zimmermann S and Moelling K (1999) Phosphorylation and regulation of Raf by Akt (protein kinase B). Science 286: 1741-1744

9. Michaud NR, Fabian JR, Mathes KD and Morrison DK (1995) 14-3-3 is not essential for Raf- 1 function: identification of Raf- 1 proteins that are biologically activated in a 14-3-3- and Ras- independent manner. Mol. Cell. Biol. 15: 3390 3397

10. Dudley DT, Pang L, Decker SJ, Bridges AJ and Saltiel AR (1995) A synthetic inhibitor of the mitogen-activated protein kinase cascade. Proc. Natl. Acad. Sci. USA 92: $7686-7689$

11. Favata MF, Horiuchi KY, Manos EJ, Daulerio AJ, Stradley DA, Feeser WS, Van Dyk DE, Pitts WJ, Earl RA, Hobbs F, Copeland RA, Magolda RL, Scherle PA and Trzaskos JM (1998) Identification of a novel inhibitor of mitogen-activated protein kinase kinase. J. Biol. Chem. 273: 18623-18632

12. Duncia JV, Santella 3rd JB, Higley CA, Pitts WJ, Wityak J, Frietze WE, Rankin FW, Sun JH, Earl RA, Tabaka AC, Teleha CA, Blom KF, Favata MF, Manos EJ, Daulerio AJ, Stradley DA, Horiuchi K, Copeland RA, Scherle PA, Trzaskos JM, Magolda RL, Trainor GL, Wexler RR, Hobbs FW and Olson RE (1998) MEK inhibitors: the chemistry and biological activity of U0126, its analogs, and cyclization products. Bioorg. Med. Chem. Lett. 8: 2839-2844

13. Kawada M, Yamagoe S, Murakami Y, Suzuki K, Mizuno S and Uehara Y (1997) Induction of p27Kip1 degradation and anchorage independence by Ras through the MAP kinase signaling pathway. Oncogene 15: 629-637

14. Hoshino R, Tanimura S, Watanabe K, Kataoka T and Kohno M (2001) Blockade of the extracellular signal-regulated kinase pathway induces marked G1 cell cycle arrest and apoptosis in tumor cells in which the pathway is constitutively activated. Up-regulation OF p27Kip1. J. Biol. Chem. 276: 2686-2692

15. Ballif $B A$ and Blenis $J(2001)$ Molecular mechanisms mediating mammalian mitogen-activated protein kinase (mapk) kinase (mek)-mapk cell survival signals. Cell Growth Differ 12: 397-408

16. Her JH, Lakhani S, Zu K, Vila J, Dent P, Sturgill TW and Weber MJ (1993) Dual phosphorylation and autophosphorylation in mitogen-activated protein (MAP) kinase activation. Biochem. J. 296: 25-31

17. Kerr JF, Wyllie AH and Currie AR (1972) Apoptosis: a basic biologica phenomenon with wide-ranging implications in tissue kinetics. Br. J. Cancer 26: $239-257$

18. MacKeigan JP, Collins TS and Ting JP (2000) MEK inhibition enhances paclitaxel-induced tumor apoptosis. J. Biol. Chem. 275: 38953-38956

19. Young RC and DeVita VT (1970) Cell cycle characteristics of human solid tumors in vivo. Cell and Tissue Kinetics 3: 285-290

20. Lenferink AE, Simpson JF, Shawver LK, Coffey RJ, Forbes JT and Arteaga CL (2000) Blockade of the epidermal growth factor receptor tyrosine kinase suppresses tumorigenesis in MMTV/Neu+MMTV/TGF-alpha bigenic mice. Proc. Natl. Acad. Sci. USA 97: 9609-9614 
21. Kamakura S, Moriguchi T and Nishida E (1999) Activation of the protein kinase ERK5/BMK1 by receptor tyrosine kinases. Identification and characterization of a signaling pathway to the nucleus. J. Biol. Chem. 274: 26563-26571

22. Mody N, Leitch J, Armstrong C, Dixon J and Cohen P (2001) Effects of MAP kinase cascade inhibitors on the MKK5/ERK5 pathway. FEBS Lett 502: 21-24

23. Kato Y, Kravchenko VV, Tapping RI, Han J, Ulevitch RJ and Lee JD (1997) BMK1/ERK5 regulates serum-induced early gene expression through transcription factor MEF2C. EMBO J. 16: 7054-7066

24. Borsch-Haubold AG, Pasquet S and Watson SP (1998) Direct inhibition of cyclooxygenase- 1 and -2 by the kinase inhibitors SB 203580 and PD 98059 . SB 203580 also inhibits thromboxane synthase. J. Biol. Chem. 273: 28766-28772

25. Reiners JJ Jr, Lee JY, Clift RE, Dudley DT and Myrand SP (1998) PD98059 is an equipotent antagonist of the aryl hydrocarbon receptor and inhibitor of mitogenactivated protein kinase kinase. Mol. Pharmacol. 53: 438-445

26. Hida T, Kozaki K, Muramatsu H, Masuda A, Shimizu S, Mitsudomi T, Sugiura T, Ogawa M and Takahashi T (2000) Cyclooxygenase-2 inhibitor induces apoptosis and enhances cytotoxicity of various anticancer agents in non-small cell lung cancer cell lines. Clin Cancer Res 6: 2006-2011

27. Sorrells DL, BlackDR, Meschonat C, Rhoads R, De Benedetti A, Gao M, Williams BJ and Li BD (1998) Detection of elF4E gene amplification in breast cancer by competitive PCR. Ann Surg Oncol 5: 232-237
28. Dent $P$ and Grant $S$ (2001) Pharmacologic interruption of the mitogen-activated extracellular- regulated kinase/mitogen-activated protein kinase signal transduction pathway: potential role in promoting cytotoxic drug action. Clin. Cancer Res. 7: $775-783$

29. Guise S, Braguer D, Carles G, Delacourte A and Briand C (2001) Hyperphosphorylation of tau is mediated by ERKactivation during anticancer drug-induced apoptosis in neuroblastoma cells. J. Neurosci. Res. 63: 257-267

30. Okano J and Rustgi AK (2001) Paclitaxel induces prolonged activation of the ras/ mek/erk pathway independently of activating the programmed cell death machinery. J. Biol. Chem. 276: 19555-19564

31. Lieu CH, Liu CC, Yu TH, Chen KD, Chang YN and Lai YK (1998) Role of mitogenactivated protein kinase in taxol-induced apoptosis in human leukemic U937 cells. Cell Growth Differ 9: 767-776

32. Kastan MB, Zhan Q, el-Deiry WS, Carrier F, Jacks T, Walsh WV, Plunkett BS, Vogelstein B and Fornace Jr AJ. (1992) A mammalian cell cycle checkpoint pathway utilizing p53 and GADD45 is defective in ataxia-telangiectasia. Cell 71: $587-597$ 